BENM 2021

International Scientific and Practical Conference "Biotechnology, Ecology, Nature Management"

\title{
INTEGRATION OF WATER BODIES INTO THE STRUCTURE OF PUBLIC URBAN SPACES
}

\author{
V. A. Kurochkina (a)*, S. K. Khlebnikov (b), M. D. Melnikova (c) \\ *Corresponding author \\ (a) National Research Moscow State University of Civil Engineering, Moscow, Yaroslavskoe shosse, 26, Russia, \\ kurochkina.mgsu.ru@yandex.ru \\ (b) National Research Moscow State University of Civil Engineering, Moscow, Yaroslavskoe shosse, 26, Russia, \\ s.xlebnikov@mail.ru \\ (c) Russian Economic University named after G.V. Plekhanov, Moscow, Stremyanny lane, 36, Russia \\ margo24102002@yandex.ru
}

\begin{abstract}
Most of the cities standing on rivers are currently faced with the problem of the formation of near-water depressed spaces. Most often, coastal areas that were previously used for agricultural and industrial needs become depressive spaces. After the loss of their purpose, these facilities cease to operate, which leads to negative environmental impact on the environment and to its gradual degradation. The article presents the results of a study of the depressive territory of the Chermyanka River section (Moscow), in which the authors took part. The section of the river is located in the North-Eastern Administrative District of Moscow in the municipal districts of Bibirevo and Otradnoye. Based on the results of the reconnaissance survey and sociological research, the main problems of the studied depressed territory were identified. Based on the analysis of successful domestic and foreign projects for the revitalization of depressive nearwater areas, ways of solving these problems and the development of a degrading territory are proposed. The article describes in detail the variant of the reorganization of the depressed territory under consideration, developed by the authors. The choice of regionalization of the river territory into green and open public spaces is substantiated, including the assessment of the morphometric indicators of the river, biological, sociological and landscape characteristics. The functional content of public spaces is described, aimed at meeting the needs of various social and age groups, and communications that allow to combine open public and green spaces into an integral recreational complex.
\end{abstract}

2672-8575 (c) 2022 Published by European Publisher.

Keywords: Environmental engineering survey, public space, revitalization, renovation, water body 


\section{Introduction}

Since ancient times, water bodies have been centers for the formation of settlements. Rivers and lakes served as sources of fresh water for both cooking and agriculture. Also, the places of confluence of rivers were often strategically advantageous. In the Middle Ages, water bodies served as natural obstacles to defensive operations and as trade routes in peacetime. With the development of industry, rivers began to be used as sources of mechanical energy and sources of water needed in various industrial operations. Thus, water bodies have always been a key link in urbanization. Rivers are an integral part of the structure and culture of most cities, influencing their spatial development and ecological state (Yankovskaya \& Andreeva, 2018).

The overwhelming majority of coastal areas of rivers located within the city limits were used by industrial, transport and agricultural enterprises. Warehouses, factories, factories, port facilities and shipyards were built on these territories, later parking lots and landfills appeared. Currently, most of these enterprises are already fully or partially closed, and together with the surrounding unexploited territories, they represent abandoned depressive spaces (Kurochkina, 2020a). Signs of "depression" include:

- The presence on the territory of abandoned, destroyed or dilapidated structures with varying degrees of wear and tear, as well as empty areas and unauthorized dumps.

- Long-term decline in environmental quality indicators.

- Lack of conditions for independent resolution of the current crisis situation without outside influence.

At present, the problem of the improvement of depressed territories is urgent all over the world. One of the most ambitious projects for the revitalization of near-water depressive spaces is a comprehensive plan for the transformation of the water space and the adjacent territory of New York (Vision 2020: New York City Comprehensive Waterfront Plan, n.d.). Most of the residential areas of the city were cut off by industrial areas from water bodies. To solve this problem, a comprehensive plan for the revitalization of coastal depressed areas was developed, which assumes that organized open spaces will be an integral complex of open public spaces, and not separate projects (Figure 1).

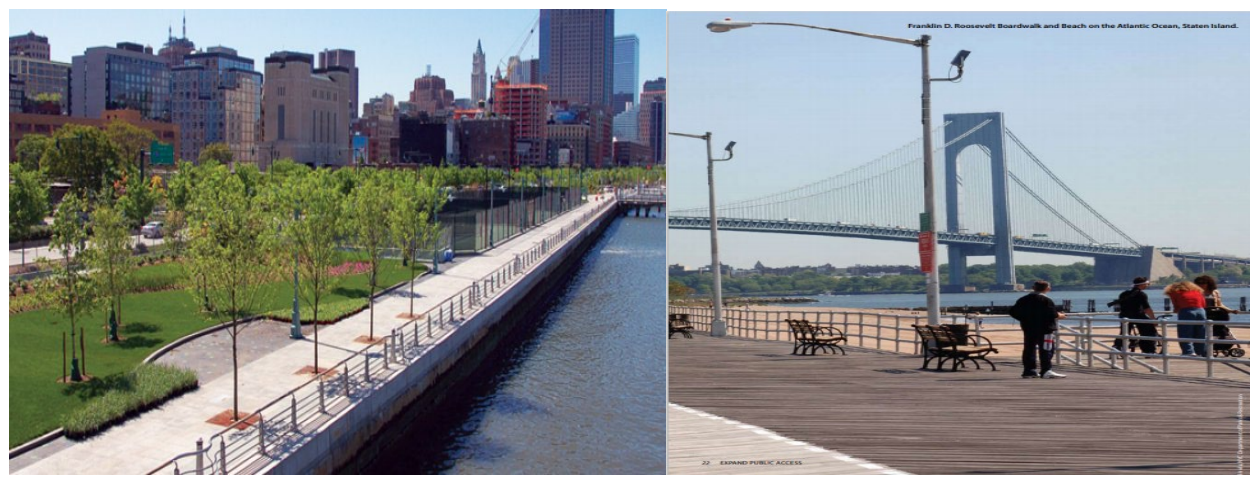

Figure 1. Public Spaces in New York: Organizing the Water Space and Adjacent Areas

In Europe and America, projects for the reorganization of near-water depressed areas have been successfully developed and implemented for more than 15 years. The large-scale project in Hamburg, the 
implementation of which was launched in 2001 (Figure 2), can also be referred to as successful projects for the development of depressed areas. The formation of the European Union led to a decrease in the turnover of the port of Hamburg, so the port territories were transformed into a residential area HafenCity, the main attraction of which was the Philharmonic (HafenCity..., n.d.). For twenty years, this urban area reconstruction project has been the largest in Europe in terms of area.

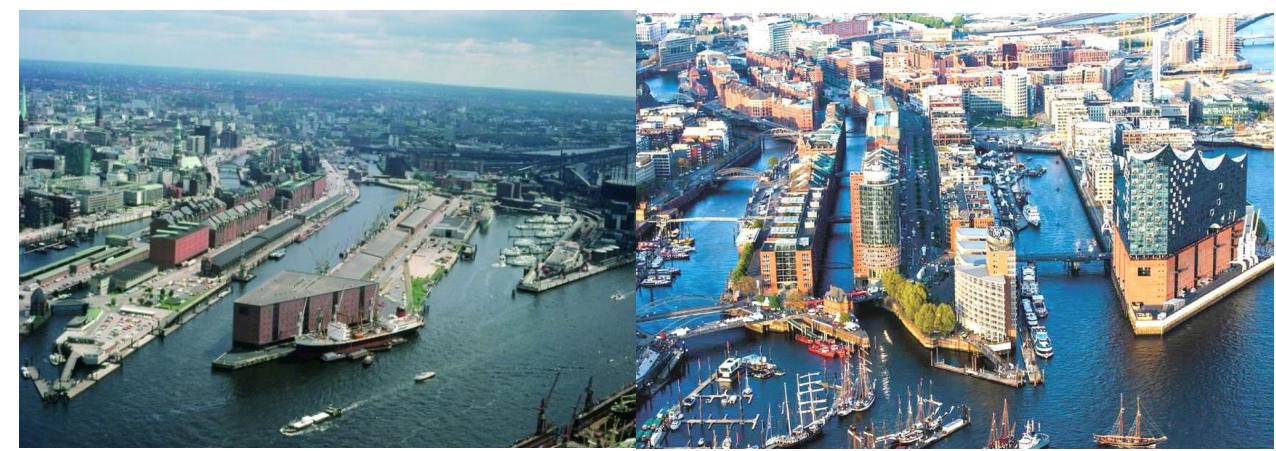

Figure 2. Residential area HafenCity: before and after revitalization

In recent years, in our country, questions have also been raised more and more often about the need to revitalize near-water depressed spaces. In Central Russia, one of the striking examples of successful landscaping of near-water areas is the Kazanskaya embankment in the city of Tula. The coastal area of the old channel of the Upa River, which for a long time belonged to an arms factory, was a depressed space. For decades, the unused territory turned into a dump. However, in 2016, the coastal territories were transferred to the residents of the city, and by September 2018 they were turned into the best open urban space of the city of Tula - Kazanskaya embankment (Reconstruction of the embankment.., n.d.) (Figure 3).

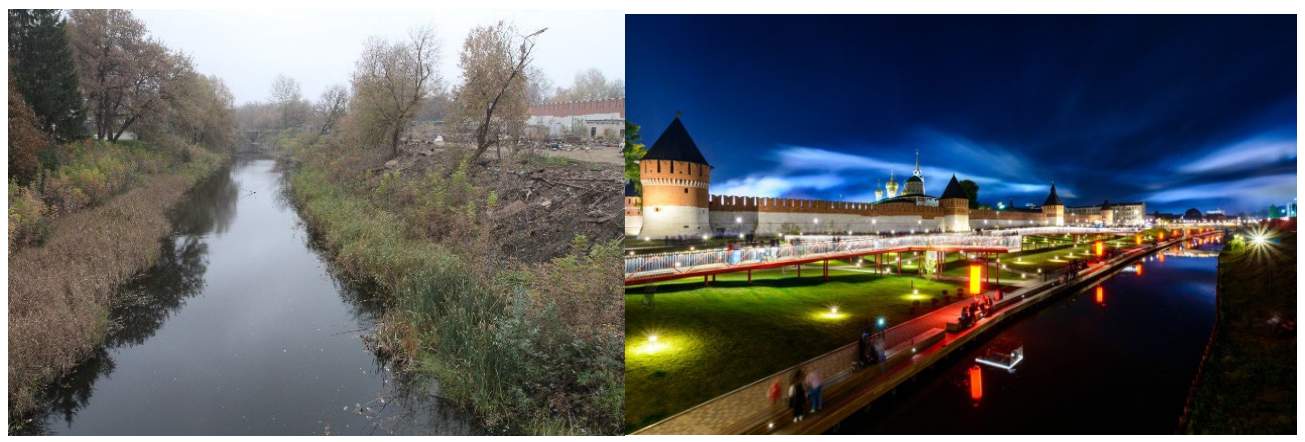

Figure 3. Kazanskaya embankment in Tula: before and after biorevitalization

The revitalization of depressive spaces is especially active in Moscow. One of the largest projects in the capital is the Yauza Park. A significant part of the coastal areas of the Yauza have already been landscaped, but the park project provides for the development of the territories and its tributaries. One of the depressive areas in need of reorganization and development is the section of the Chermyanka River, selected for research (Figure 4). The object of consideration is located in the North-Eastern Administrative District of Moscow in the municipal districts "Bibirevo" and "Otradnoye". In the interval 
from st. The coastal area of the river, wide up to the passage of Dezhnev, is an unexploited area overgrown with small and large vegetation. The ecological state of the study area is also worsened by a large number of unauthorized dumps of construction and household waste from garage cooperatives, formed on the left bank of the Chermyanka.

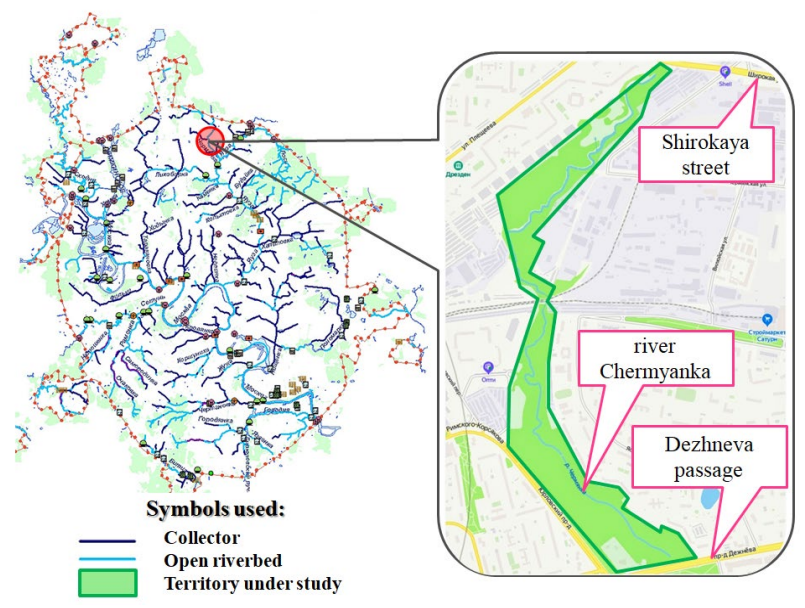

Figure 4. The object of the study is on the scheme of the collector-river network of the city of Moscow. Section of the Chermyanka river from st. Wide to Dezhnev's passage (drawing by the authors)

Thus, there is an obvious degradation of the Chermyanka river valley. Also, a large number of unidentified tributaries and collectors discharging wastewater and, presumably, man-made waste, have a negative technogenic impact on this area; therefore, these territories can be considered as an uncontrollable natural and technical system (NTS). The development of spontaneous NTS in most cases follows the path of environmental degradation (Khlebnikov \& Suzdaleva, 2020). For the development of near-water depressed areas, it is necessary to make this NTS manageable; for this purpose, it is proposed to organize an open public space, which will be the ecological regulator of the NTS (Suzdaleva, 2016).

\section{Purpose of the Study}

On the investigated depressive territory, the authors of the article conducted a reconnaissance engineering and environmental survey. This paper analyzes the results of the stages of the study, as well as suggests ways of reorganization and ideas for further improvement of the studied section of the Chermyanka River.

Depressive spaces formed near water bodies should be separated into a separate group. Such territories have a special socio-economic and often ecological potential. Water bodies have a number of properties useful for urban planning. Water enhances the impression of an architectural object and makes it diverse, having a beneficial effect on the mental state of a person (Bazina, 2017). For this reason, nearwater depressed areas are advisable to use for the organization of open public spaces ("public open spaces"). 


\section{Research Methods}

In the absence of abandoned and destroyed structures in empty natural areas rich in natural vegetation and with favorable relief, it is economically and environmentally beneficial to organize green open spaces ("open green spaces"). In the presence of dilapidated structures and in areas with poorly expressed woody vegetation, it is advisable to organize urban open spaces ("urban open spaces"), including embankments, boulevards, squares and parks. In the presence of unexploited buildings with sufficient strength characteristics, low wear and tear, as well as architectural value, it is possible to form closed public spaces ("public closed spaces") (Kurochkina, 2020b). A detailed classification of public spaces is shown in Figure 5.

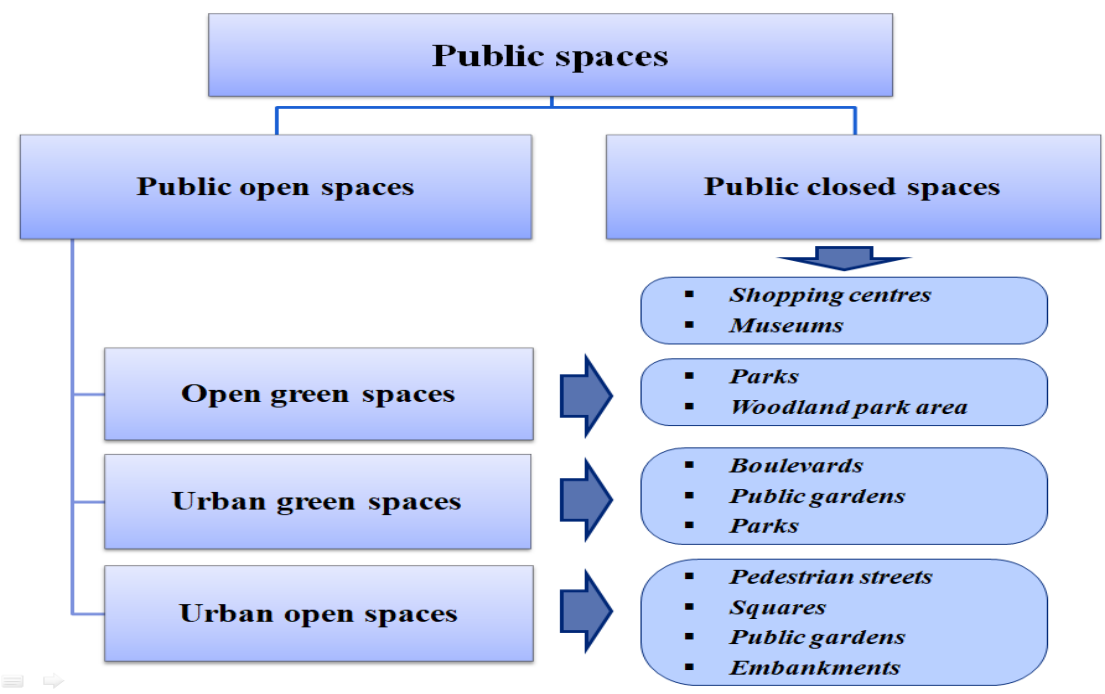

Figure 5. Classification of public spaces (drawing by the authors)

According to the theory of sustainable development, humanity should strive to improve the comfort and safety of the environment. Reorganizing depressive spaces is one way to achieve this goal. It will provide people with a high-quality, favorable and safe living environment (Kurochkina, 2020a). There are many ways to restore depressive spaces and objects. It is possible to identify the main types of urban space improvement aimed at transforming existing urban planning systems:

Renovation is the renewal of territories through redevelopment, which includes a significant change in the idea (concept) of a territory project, or a real estate object, and any of its characteristics, aimed at increasing its value and attractiveness for consumers (Antyufeev \& Ptichnikova, 2017; Telichenko, 2020). As a rule, it affects small areas, individual objects and closed spaces.

Revitalization is the "revitalization" of no longer functioning territories or objects through the disclosure of new possibilities of old forms, taking into account their updated modern functions (Shalina \& Stepanova, 2019). Most often, it is aimed at organizing open public spaces that ensure the formation of a single urban planning environment that connects urban development with the landscape. This approach allows for a balance between the opinions of stakeholders (including the population) and restructuring (Larsen, 2009). 
Redevelopment is a purposeful material change of existing real estate or landscape aimed at changing their class and / or functional purpose, as a result of which an object or territory acquires qualitatively new properties and characteristics that increase their value (Shalina \& Stepanova, 2019). As a rule, it is accompanied by significant changes in the original concept, which make it possible to create the best landscape from ecologically disturbed territories and use it as productively as possible (Loures, 2015).

Recently, depressive spaces located near water bodies have become objects of renovation and revitalization. An example of such a space is the section of the river. Chermyanki selected for research.

The considered section consists of two sections: from the street. Wide to the Beskudnikovo Medvedkovo railway line, which is $1.6 \mathrm{~km}$ long, and from the Beskudnikovo - Medvedkovo railway line to Dezhnev passage, $1.5 \mathrm{~km}$ long. The second section has the status of a natural complex of the city of Moscow.

The study carried out included:

- Reconnaissance survey of the river channel and adjacent territories (period: 12.11.2020 20.11.2020)

- Sociological survey of residents of nearby residential areas (residents of Bibirevo and Otradnoye districts) (period: 02/08/2021 - 02/09/2021)

During the reconnaissance survey, the study area was divided into 28 sections, which was necessary for a more accurate description of the river valley. Chermyanka (figure 6). Reconnaissance work was carried out by the authors of the article for three days. Productivity survey on both banks of the river. At each site, the morphometric indicators of the river and channel were recorded (width, depth, current velocity, silting of the bottom, as well as the presence of tributaries, drains of unidentified origin and bank protection structures), geoecological indicators of coastal areas and spots, the presence of swampy areas and other water manifestations), as well as a number of sociological and biological indicators (the presence of recreation areas, the presence of animals, the area of projective cover with herbaceous vegetation). Particular attention was paid to the possibility of approaching water, terrain, as well as the presence of trees and shrubs.

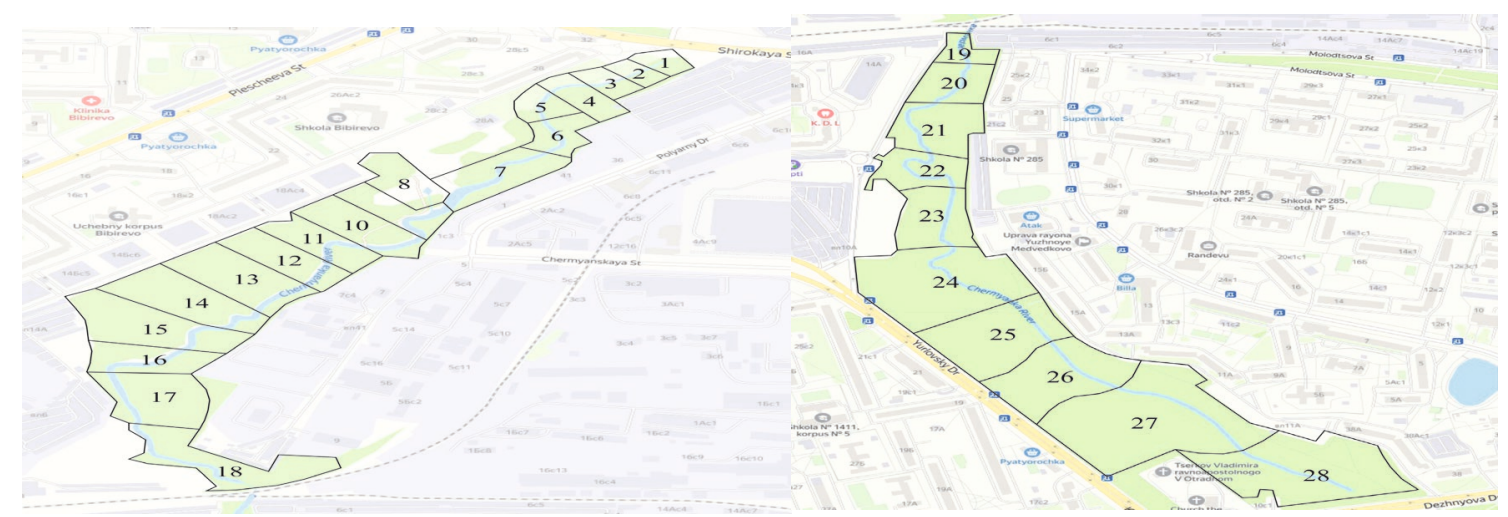

Figure 6. Schematic map of the location of the survey sites. On the left - segment 1, on the right - segment 2 (drawing by the authors) 


\section{Findings}

During the reconnaissance survey, the heterogeneity of the study area was revealed in many parameters that play a significant role in choosing the type of public space that can be organized in these areas. These factors include: type and density of vegetation; the type of bank protection structures and their presence; as well as landscape characteristics. For example, to organize a green open space (park zone) in the shortest possible time, it is advisable to use coastal areas in their natural state (that is, without gabion-type bank protection structures), which at the same time have predominantly woody vegetation. Also of great importance is the high passability of the terrain or the potential of the coastal territories to ensure it. Areas that do not meet the above characteristics can be converted into open public spaces. In this case, a partial or complete change in the functions and appearance of the environment is allowed (Figure 7). Such an integrated approach can contribute to the formation of an aesthetically complete environment, in which the water urban space is considered as an important element in the general planning of the city, as a place of social activity of the city and a place of intensive recreation (Krautzberger, 2007; Topfstedt, 1991).

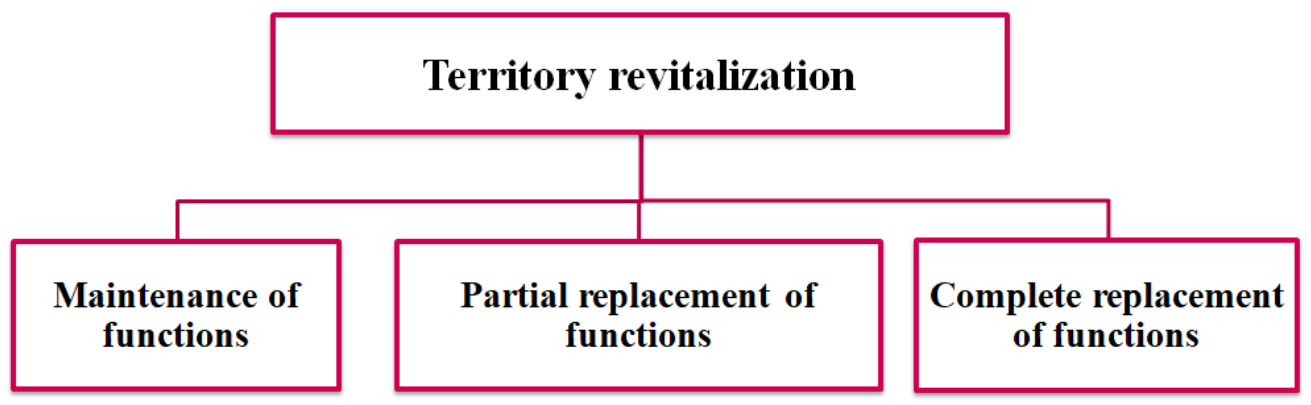

Figure 7. Territory transformation models (drawing by the authors)

Also, when conducting field observations, taking into account indirect factors, it was determined that the level of seasonal water rise in the river reaches 1 meter. Further research is needed, including during floods, to determine the maximum water level in the river and to develop a number of constructive measures to avoid seasonal flooding of the new public space.

In order to identify the needs of the population, the authors of the work carried out sociological research among residents of areas adjacent to the studied section of the river. The age of the respondents ranged from 14 to 84 years old. Based on the data obtained (both our own and a number of other researchers), the following conclusions were drawn:

- The greatest need for open public spaces is felt by the residents of the Bibirevo district. This need decreases as we move towards the Dezhnev passage. Thus, residents of Otradnoye believe that there are enough open public spaces in their area (for example, the already ennobled territories of the Chermyanka River, located beyond the Dezhnev Passage). However, regardless of the area of residence, $85 \%$ of the respondents consider it necessary to improve the studied territories of Chermyanka.

- These territories, despite their litter of MSW, lack of landscaping and the presence of invasive species of poisonous plants (hogweed), are places of recreation for the population. This is confirmed both 
by the results of the surveys and by the presence of walking trails and picnic areas with campfires arranged by the population.

- According to the population, the main problems of these territories (Park Yauza, 2020) are (Figure 8):

- lack of landscaping

- contamination of territories

- lack of lighting

- lack of engineering structures performing connecting functions between the banks

- lack of places for garbage collection

- unsafe environment

- The most popular types of public spaces, according to a sociological survey (Fig. 8), were the embankment ( $80 \%$ of respondents indicated the need to organize such a public space) and a park zone $(64 \%)$. The cycling trail $(60 \%)$ and the network of pedestrian paths will allow uniting these spaces into an integral complex.

The respondents paid special attention to the necessity of organizing playgrounds for young and middle-aged children, organizing sports grounds, as well as preserving the landscape that allows the organization of unauthorized tubing trails in winter.

Based on the above, there are several main areas of activity in the revitalization of the study areas:

- Ensuring adequate lighting levels

- Providing inter-coastal communications through a significant increase in the number of bridges

- Arrangement of a pedestrian zone with a high-quality paved surface (a developed network of paths and alleys)

- Development of sports infrastructure (sports grounds and equipment, bike trail)

- Organization of playgrounds

- Organization of garbage collection
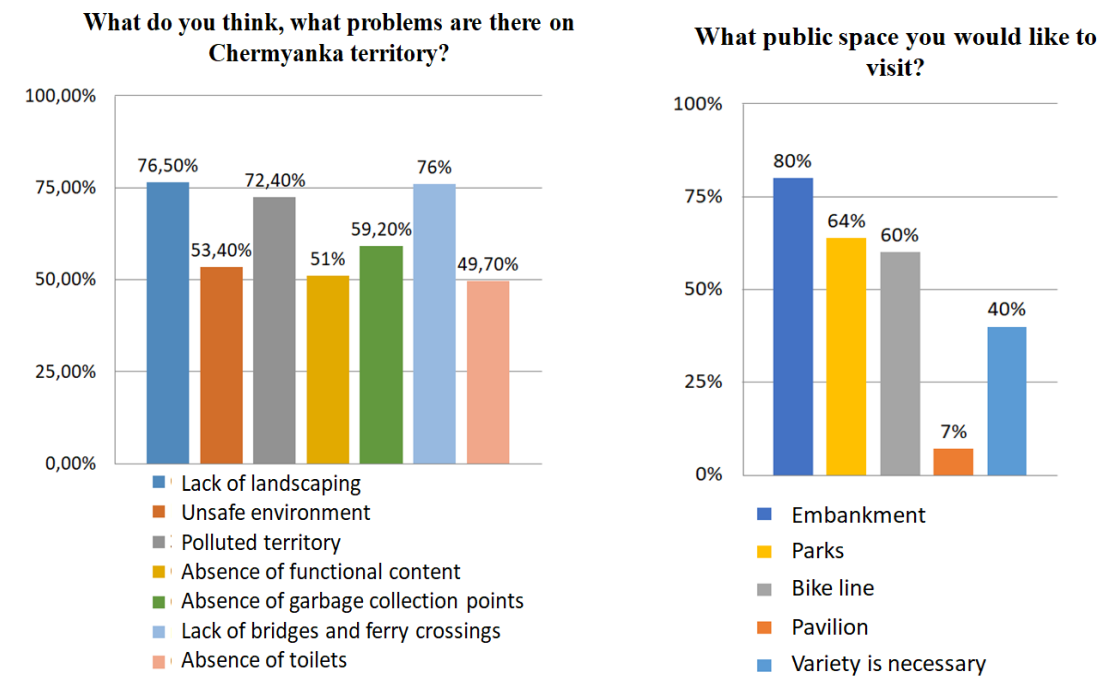

Figure 8. Sociological research results (drawing by the authors) 
During the reconnaissance survey, various pollution of the river and coastal areas were identified. In addition to the high level of littering of MSW both on the banks and part of the channel, some mechanical pollution of the aquatic environment can be noted, the presence of which can be determined visually or through indirect signs (the presence of potential sources of pollution).

Sources of such ingredient pollution are roads, car washes, garage cooperatives and a transformer substation, from which rain and melt water is drained through drainage lines (collectors, concrete, plastic and metal pipes). The main pollutants include (Kurochkina, 2020a):

- Contamination with oil and oil products (determined visually by the presence of rainbow films in places of stagnant water)

- Chloride contamination associated with the use of salts that stimulate snow melting (potentially due to sources of contamination, requires chemical analysis of water samples)

- Contamination with detergents (detergents), which can cause a violation of the oxygen regime, a change in the natural course of chemical processes, the poisoning of aquatic organisms and the suppression of life in water bodies (determined visually by the presence of foam (Figure 9), collecting on the rapids downstream than the inflow of sewage waters from a car wash located on the left bank)

- contamination by heavy metals (assumed based on the presence of sources of contamination, requires chemical analysis of water samples)

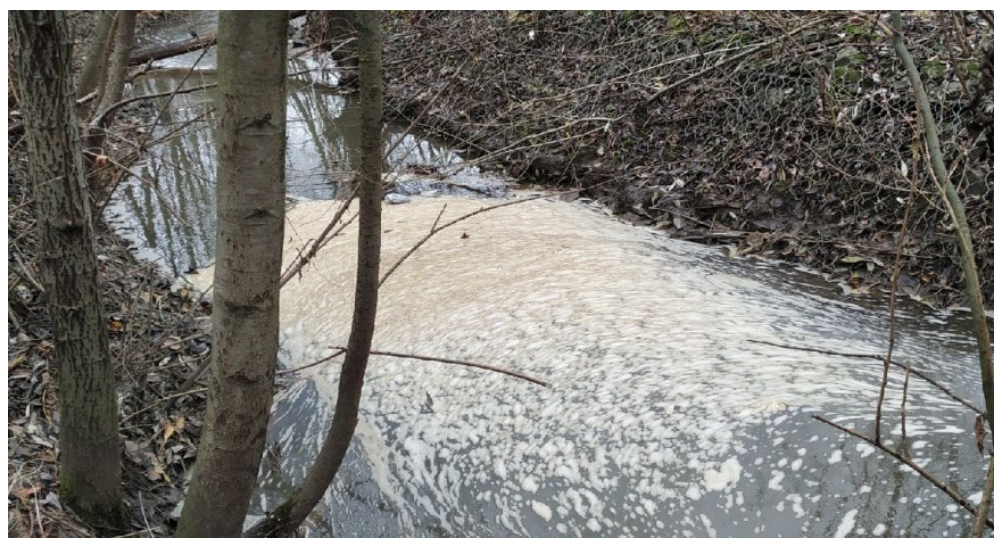

Figure 9. Suspected contamination with detergents. Accumulation of foam of unidentified origin (photo by the authors)

The aforementioned ingredient pollution is most typical for the first section of the study areas (from Shirokaya street to the railway line), since the largest number of unidentified tributaries and pipes is located in this area. Additional research is required to determine the sources of pollution to protect the river from ingredient pollution. The need is due to the fact that it is the elimination of sources of pollution or the organization of treatment facilities on their territory that can significantly reduce the level of water pollution by chemicals, as well as heavy metals (Borovkov et al., 2012; Telichenko \& Kurochkina, 2016).

For the second section of the river (from the railway line to the Dezhnev Passage), noise pollution is more typical, the source of which is the busy traffic on the Dezhnev Passage and Yurlovsky Passage. The most effective ways to combat noise pollution are the construction of noise screens and afforestation (Vision 2020: New York City Comprehensive Waterfront Plan, 2020). 
Option for reorganization of the research territory.

Based on the results of a sociological study and a reconnaissance survey, the authors developed an example of a possible zoning of the territories of the future public space (Figure 10).

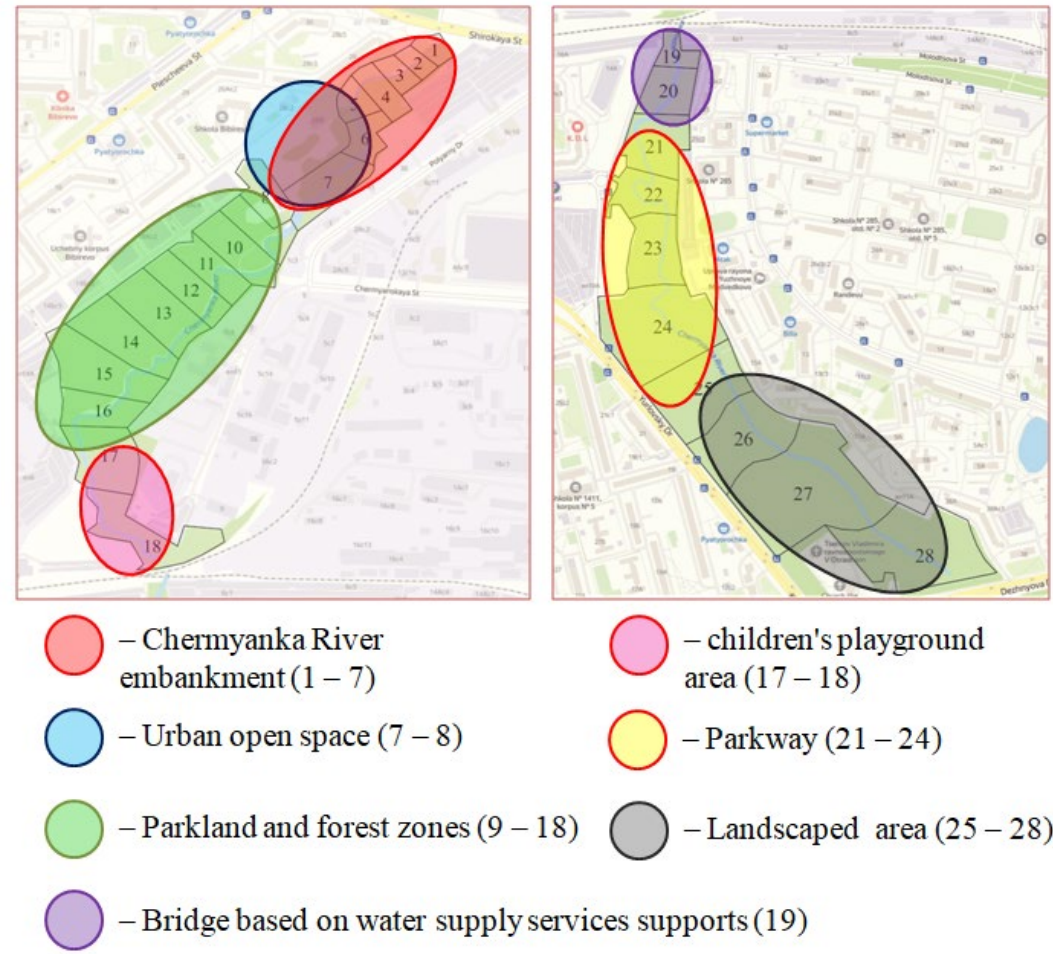

Figure 10. Schematic map of the proposed zoning of public space territories (drawing by the authors)

For zoning the territory of the Chermyanka river valley into various functional zones and types of public spaces, we will retain the previous division of the coastal territory into 28 sections, keeping their territorial boundaries and numbering.

The first plots located along the street. Pleshcheeva, have various shore protection structures. The territory is adjacent to residential buildings, and the woody vegetation on it is weakly expressed. Based on the above factors, the authors consider the organization of an open public space, namely the embankment, to be a rational option for the development of this territory. For this, it is necessary to carry out significant land work, implying a serious change in the appearance of the area. The coastal area can be improved by splitting walking paths and cycling trails, installing benches, trash bins and evening lighting.

On site 5, where Chermyanka meanders for the first time, it is proposed to place an amphitheater on the right bank of the river bend overlooking the river and the rotunda, which can serve as the architectural dominant of the open urban space. It is proposed to build a rotunda on the left bank of the bend (Figure 11). In this regard, it is necessary to conduct a geological study of the soil of the left bank of the meander for further design of the architectural structure. 

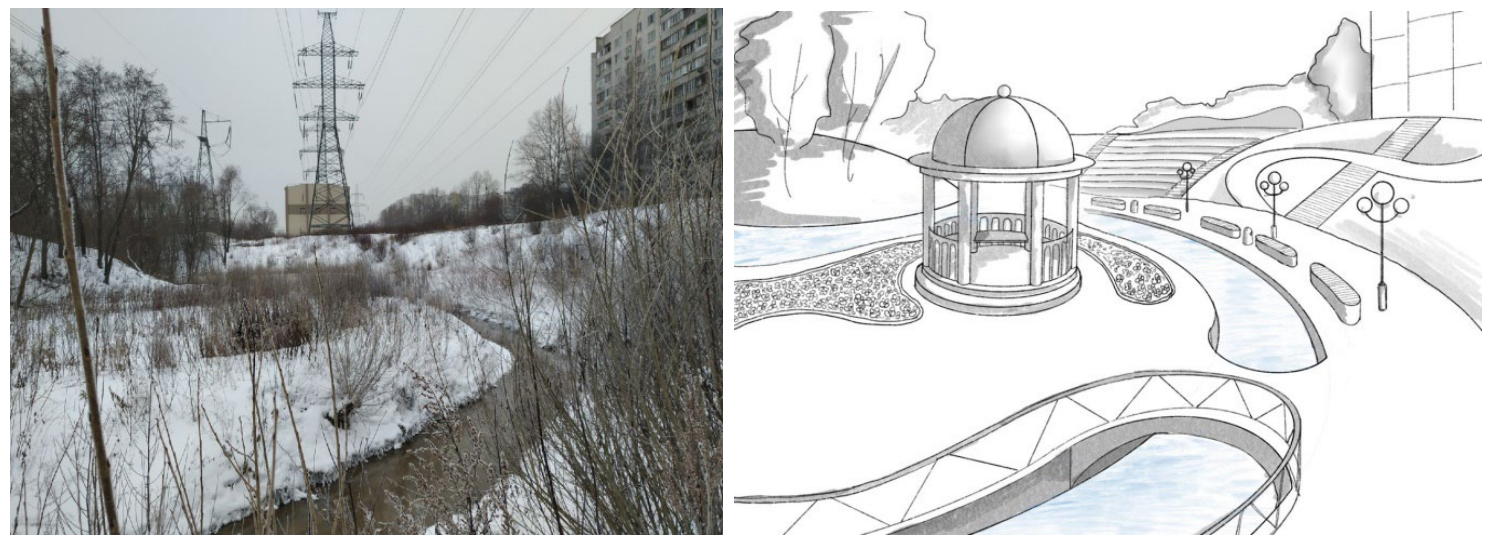

Figure 11. Embankment (U.N. 1 - U.N. 7). On the left - before reconstruction, on the right after (drawing by the authors)

The left bank of the first 7 sections is reinforced with gabion structures such as mattresses. Bank protection structures provide access to water as well as potential high terrain. Arboreal and shrub vegetation is clearly expressed in this area, which makes it possible to organize here a park area with walking paths and a bike trail. The organization of picnic areas for the recreation of visitors in the park area will also be relevant. To ensure the accessibility of each public production (embankment on the right bank and a forested area on the left), the banks should be connected by means of bridges.

The flat area located on the right bank of the 7th and 8th observation sites deserves special attention. Herbaceous vegetation predominates on it and woody vegetation is almost completely absent. Also, the territory is adjacent to residential buildings and does not have pronounced relief features. Based on these factors, the authors consider the best option for the improvement of the described site to organize an open urban space on its territory (Votinov, 2014), which serves as an entrance group to the territory of a recreational natural complex (Figure 12). Due to the close proximity to residential buildings and children's educational institutions, this area should fulfill a social function. It can house sports and playgrounds, as well as a food court. To ensure the possibility of holding various social and entertainment events in the area adjacent to the amphitheater on the 5 th site, it is proposed to install a stage.
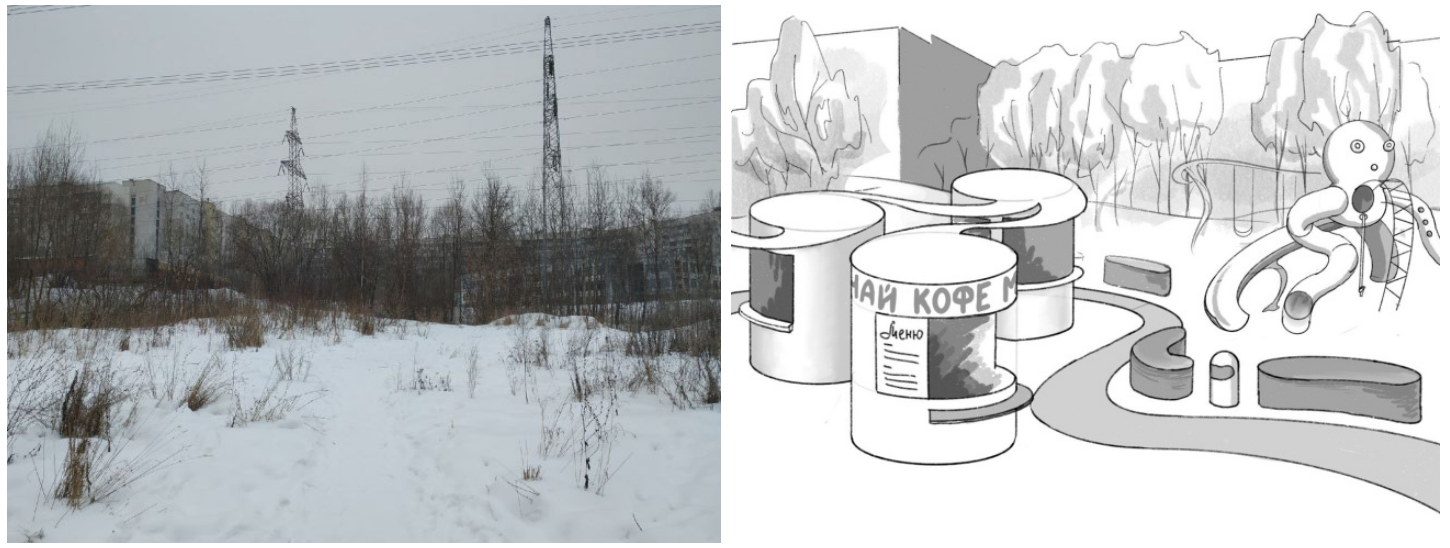

Figure 12. Open urban space (UN 7 - UN 8). On the left - before reconstruction, on the right after (drawing by the authors) 
Starting from the 9th site, the banks are in a natural state, and there are no bank protection structures. Also, shrub and woody vegetation prevails in this area. The combination of these factors allows here the organization of a forest-park zone. To organize a green public space on this territory, it is necessary to carry out work on dividing the network of paths, bike trails and alleys, to provide evening lighting for the main walking and cycling routes. The recreational efficiency of public space can be improved by building gazebos in the bends of the river and benches along the main alley. The possibility of free movement between the banks must be ensured through the construction of new bridges across Chermyanka.

Another site of particular interest is site 18. This choice is due to the unique relief and hydrographic features of the area. The river bed bifurcates, washing a rather large island with streams. The island is hidden from the city noise by the steep slopes of the coast and is an excellent place for recreation for both adults and children.

Every child dreamed of a hut on the island, this place can make children's dreams come true, so the authors propose the construction of a playground on the island. A playground should be combined in design with both the natural environment and the technogenic filling of the public space, which will emphasize the integrity of the recreational area, which is a combination of urban and green public spaces (Figure 13). On the right slope, it is proposed to make a wooden amphitheater overlooking the island. The accessibility of the island from each side must be ensured by means of bridges.
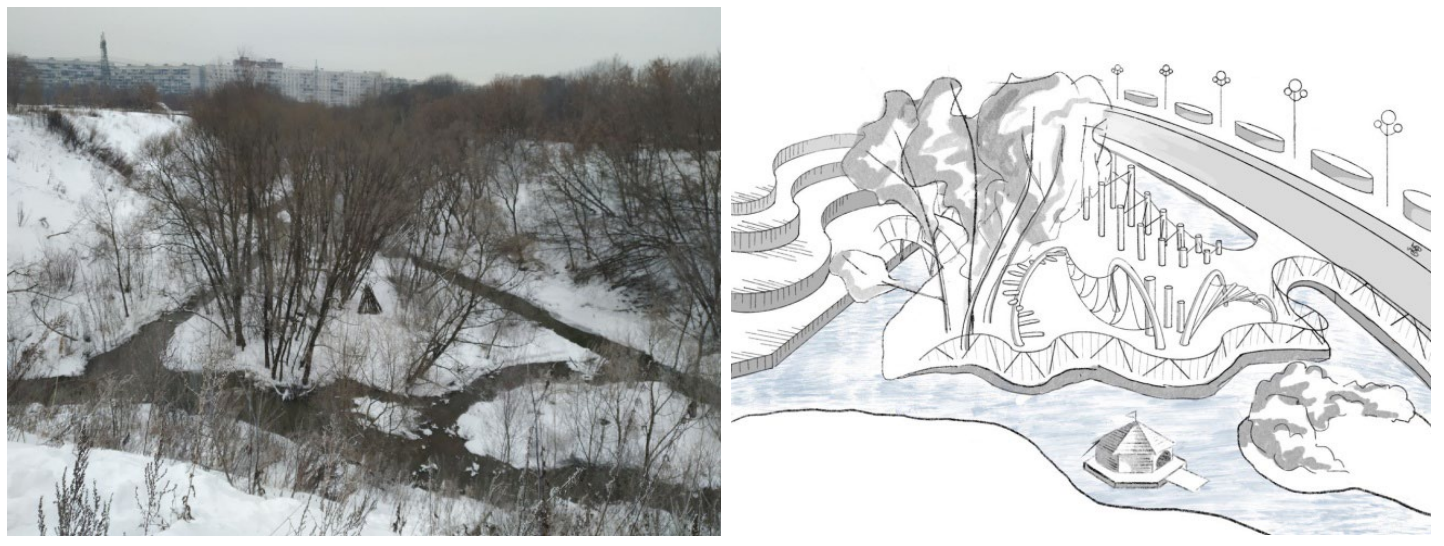

Figure 13. Island with a playground (UN 17 - UN 18). On the left - before reconstruction, on the right - after (drawing by the authors)

In the interval from the Beskudnikovo-Medvedkovo railway line to the Dezhnev passage, it is also recommended to transform the territory of the river valley into a green public space. The park area can be divided into three characteristic sections, which can be united by a bike trail and a central walking trail.

Local residents tried to use hot water supply and heating pipes located on the border of sections 19 and 20 as a bridge to cross from one river bank to another. This is due to the insufficient number of crossings throughout the study area. In order to organically integrate water supply and sewerage communications into the natural and technical park system as well as the construction of a pedestrian bridge, it is proposed to organize a pedestrian bridge on the support of heating pipes (Figure 14). When designing a structure, it is important to pay attention to the need to provide access to pipes for monitoring 
the technical condition of the structure and repair work. It is also desirable to avoid pressure on the pipes of the bridge structure and pedestrians.
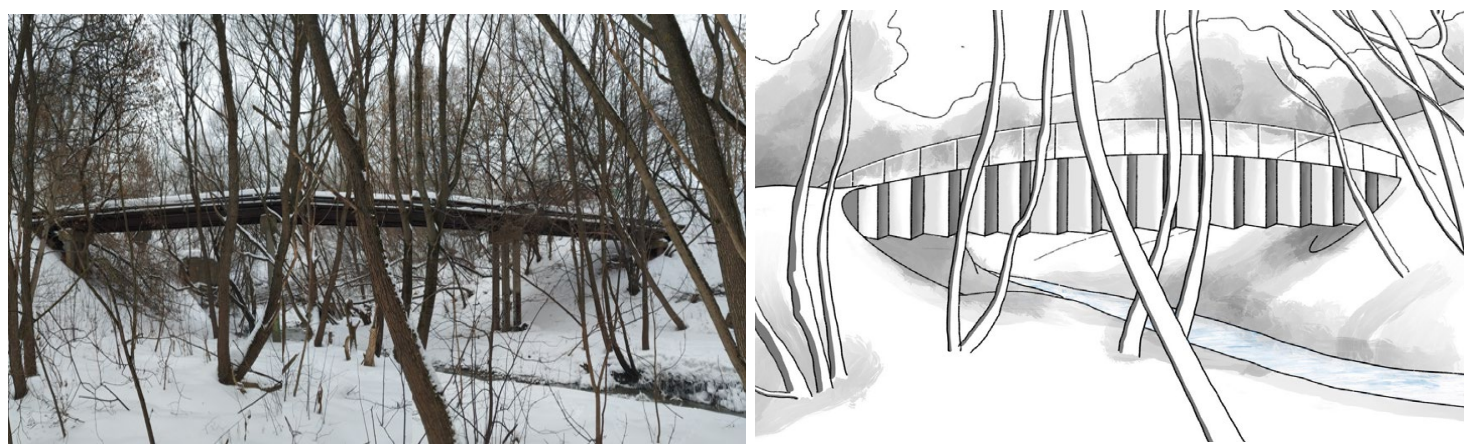

Figure 14. Bridge on the basis of pillars of water supply communications (UN 19). Above - before reconstruction, below - after (drawing by the authors)

Similarly with sections $9-18$ in sections $22-24$, it is proposed to organize a park zone with a powerful pedestrian alley, evening lighting, benches and a bicycle trail (Figure 15). Another entrance group to the territory of public production should be organized on the right bank of the 24th section, which is adjacent to the fork in Yurlovsky passage. Here, in winter, the landscape allows the organization of tubing trails. In this regard, it is worth avoiding significant excavation work in this area.
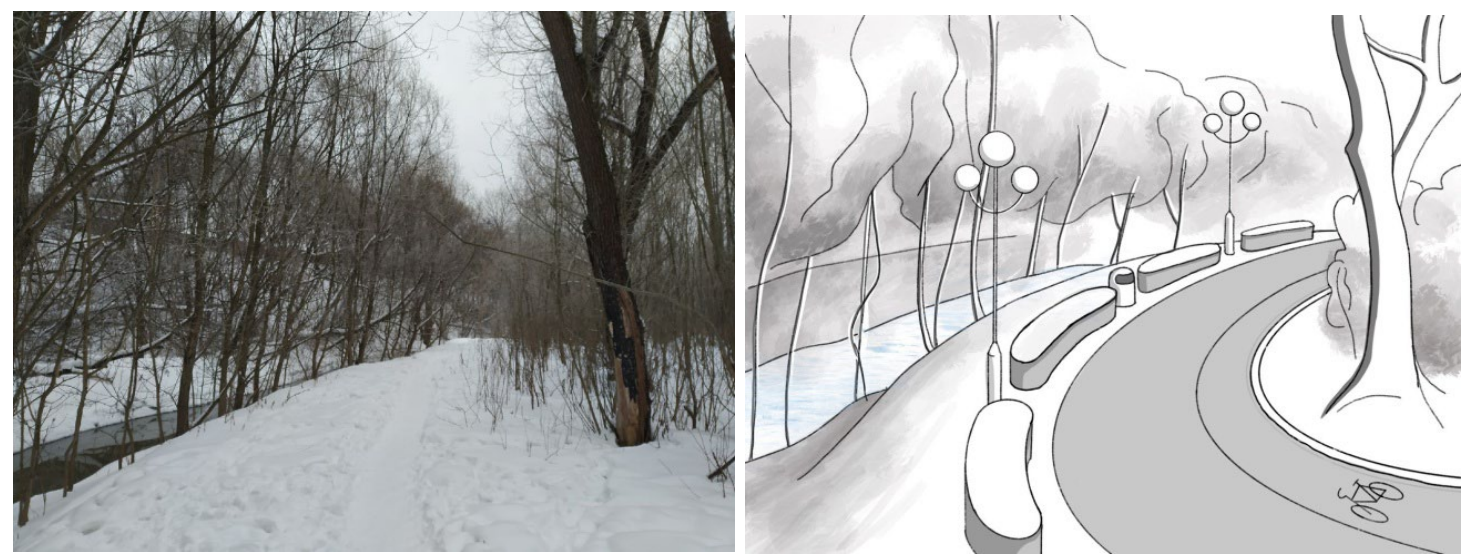

Figure 15. Park Alley (UN 21 - UN 24). On the left - before reconstruction, on the right after (drawing by the authors)

The territory of the 25-28 sites is the most well-groomed, and the factors complicating the implementation of the revitalization project are practically absent here. For this reason, in January 2021, the improvement of the described areas has already begun.

In addition to the recreational function, the new public space should also perform a communication function (Zazulia, 2021), linking the Bibirevo and Otradnoye districts with a pedestrian route, as well as ensuring free movement of people between industrial areas and residential areas located on different banks of the Chermyanka River. These functions will be ensured by an increase in the number of bridges and crossings across the river bed and its tributaries. Also an important step for the unification of the two 
sections of the river ("Shirokaya st. - railway line" and "railway line - Dezhneva pr.") Into a single open public space is the laying of a pedestrian tunnel under the railway embankment.

\section{Conclusion}

The territory of the 25-28 sites is the most well-groomed, and the factors complicating the implementation of the revitalization project are practically absent here. For this reason, in January 2021, the improvement of the described areas has already begun.

In addition to the recreational function, the new public space should also perform a communication function (Zazulia, 2021), linking the Bibirevo and Otradnoye districts with a pedestrian route, as well as ensuring free movement of people between industrial areas and residential areas located on different banks of the Chermyanka River. These functions will be ensured by an increase in the number of bridges and crossings across the river bed and its tributaries. Also, an important step for the unification of the two sections of the river ("Shirokaya st. - railway line" and "railway line - Dezhneva pr.") Into a single open public space is the laying of a pedestrian tunnel under the railway embankment.

\section{References}

Antyufeev, A., \& Ptichnikova, G. (2017). Urban regeneration of plants territories in industrial cities of Russia: a case study in Volgograd. SHS Web of Conferences 35 (ICIE-201). https://doi.org/10.1051/shsconf/20173501003

Bazina, A. N. (2017). Aspects of a phenomenological approach to architecture and design. Innovative project, 2(1), 112-119. https://doi.org/10.17673/IP.2017.2.01.11

Borovkov, V. S., Blazi, S., \& Kurochkina, V. A. (2012). Complex ecological safety of water bodies in urbanized territories. Ecology of urbanized territories, 2, 45-49.

HafenCity - die Genese einer Idee. (n.d.). Retrieved on 22 February, 2021, from https://www.hafencity.com/de/ueberblick/hafencity-die-genese-einer-idee.html

Khlebnikov, S. K., \& Suzdaleva, A. L. (2020). Environmental aspects of the construction of unique buildings and structures (railway station in Tver). Collected scientific works of the International Scientific Seminar. M.: MGSU.

Krautzberger, M. (2007). Städtebauliche Erneuerung - zum Beginn einer neuen Politik für die Städte 1990. [Urban renewal - at the beginning of a new policy for the cities 1990]. Bundesministerium für Verkehr, Bau und Stadtentwicklun: Denkmal: Alte Stadt - Neues Leben, 22-24.

Kurochkina, V. A. (2020a). Water bodies as the basis by open public spaces planning and an instrument of urban transformation. The Eurasian Scientific Journal, 5(12). https://doi.org/10.15862/63SAVN520

Kurochkina, V. A. (2020b). The impact of long-term construction subjects and industrial areas on the geoecology of cities and development of depressed urban spaces. The Eurasian Scientific Journal, 6(12). https://doi.org/10.15862/36NZVN620

Larsen, K. (2009). Revitalizing the Parramore heritage renovation area: Florida's state housing initiatives partnership program and Orlando's historic African American community. Housing Studies, 24(2), 173-201. https://doi.org/10.1080/02673030802705136

Loures, L. (2015). Post-industrial landscapes as drivers for urban redevelopment: Public versus expert perspectives towards the benefits and barriers of the reuse of post-industrial sites in urban areas. Habitat International, 45, 72-81. https://doi.org/10.1016/j.habitatint.2014.06.028

Park Yauza. (2020). Along the Pleshcheeva street to Shirokaya street. Analytical report . NPO "Vector".

Reconstruction of the embankment of the Upa River, Tula. (n.d.). Retrieved on 22 February, 2021, from https://archi.ru/projects/russia/11869/rekonstrukciya-naberezhnoi-reki-upy-tula 
Shalina, D. S., \& Stepanova, N. R. (2019). Renovation, redevelopment, revitalization and gentrification of urban space. Fundamental research, 12, 285-288.

Suzdaleva, A. L. (2016). Creation of managed natural-technical systems. ID ENERGIYA.

Telichenko, V. I. (2020). Renovation - creating modern urban environment. Proceedings of Moscow State University of Civil Engineering, 1(15). 1-1. Vestnik MGSU

Telichenko, V. I., \& Kurochkina, A. A. (2016). Methods of Estimation Technogenic Pollution of Water Bodies in Urbanized Territories. Proceedings of Moscow State University of Civil Engineering, 6, 80- 89. Vestnik MGSU. https://doi.org/10.22227/1997-0935.2016.6.80-89

Topfstedt, T. (1991). Baukultur zwischen Bestandssicherung und Stadterneuerung, in: Jahrbuch für Architektur 1991. [Building culture between securing existing buildings and urban renewal, in: Yearbook for Architecture]. Braunschweig, 9-20.

Vision 2020: New York City Comprehensive Waterfront Plan. (n.d.). Retrieved on 22 February, 2021, from https://www1.nyc.gov/site/planning/plans/vision-2020-cwp/vision-2020-cwp.page

Votinov, M. A. (2014). Features of the structure of public spaces of the urban environment. Bulletin of BSTU named after V.G. Shukhov, 4, 36-40.

Yankovskaya, Y. S., \& Andreeva, Y. K. (2018). Kostroma - Formation of Town-Planning Identity: City and Rivers, History and Contemporaneity. Architecture and Modern Information Technologies, 4(45), 314-328. http://marhi.ru/eng/AMIT/2018/4kvart18/22_jankovskaja/index.php

Zazulia, V. S. (2021). Problems and Trends in the Development of Public Spaces: Domestic and Foreign Experience. Urbanism, 1, 56-72. https://doi.org/10.7256/2310-8673.2021.1.34516 